\title{
The Effect of Thermooxidative Aging on the Durability of Glass Fiber-Reinforced Epoxy
}

\author{
Amin Khajeh, ${ }^{1}$ Faizal Mustapha, ${ }^{1,2}$ Mohamed Thariq Hameed Sultan, ${ }^{1,2}$ \\ György Bánhegyi, ${ }^{3,4}$ Zsuzsanna Karácsony, ${ }^{4}$ and Viktor Baranyai ${ }^{4}$ \\ ${ }^{1}$ Department of Aerospace Engineering, Universiti Putra Malaysia, 43400 Serdang, Selangor, Malaysia \\ ${ }^{2}$ Aerospace Manufacturing Research Center (AMRC), Level 7, Tower Block, Faculty of Engineering, UPM, \\ 43400 Serdang, Selangor, Malaysia \\ ${ }^{3}$ Medicontur Medical Engineering Ltd., Herceghalmi Road, Zsámbék 2072, Hungary \\ ${ }^{4}$ Bay Zoltan Nonprofit Ltd. for Applied Research, Fehérvári Út 130, Budapest 1116, Hungary
}

Correspondence should be addressed to Amin Khajeh; aminkhajeh@gmail.com

Received 5 September 2015; Accepted 15 November 2015

Academic Editor: Katsuyuki Kida

Copyright (C) 2015 Amin Khajeh et al. This is an open access article distributed under the Creative Commons Attribution License, which permits unrestricted use, distribution, and reproduction in any medium, provided the original work is properly cited.

Thin-skinned organic matrix composites within aeronautical structures are subjected to thermooxidative aging during their service life, leading to reductions in their durability. In this paper, a durability evaluation of fiberglass epoxy prepreg is performed on the original composite thickness before and after $800 \mathrm{~h}$ isothermal aging at $82^{\circ} \mathrm{C}$. The characterization of both aged and unaged composites comprised tensile tests, DMA, FTIR, weight loss measurements, SEM, and DSC. The tensile strength and modulus of the composites increased after being exposed to pronounced aging conditions, whereas a decrease was observed in the toughness. DMA results revealed that the glass transition temperature and rubbery state modulus increased as a result of the thermooxidative aging. FTIR spectroscopy demonstrated the formation of carbonyl compounds due to oxidation of the chemical structure of the resin. SEM observations indicated the existence of minor superficial cracking and poor fiber-matrix adhesion after aging. In addition, a minor mass change was observed from mass loss monitoring methods. The overall findings suggest that postcuring and physical aging enhanced the brittleness of the resin, leading to a significant decline in the useful structural life of the thin-skinned composite.

\section{Introduction}

The importance of persistently improving civil aircraft performance and improving fuel consumption has resulted in novel improvement in the designs of aeronautical structures. This improvement has also led to a drastic growth in the application of advanced materials. Consequently, aeronautical industries have begun to use thin-skinned polymer matrix composite materials in aircraft construction. The Boeing 787 and Airbus A380 aircraft pioneered this innovative structural design. Such high speed civil aircraft offer considerable promise of being able to withstand long-term $(60,000 \mathrm{~h})$ exposure [1-5] to temperatures ranging from -40 to $177^{\circ} \mathrm{C}$ [5] and being sufficiently ductile to absorb low velocity impact energies [6-10]. However, during thermal aging at moderate temperatures, for example, below the glass transition temperature, organic matrix composites deteriorate by matrix embrittlement resulting from thermooxidative degradation [11]. Importantly, because oxidation is a diffusion-related phenomenon [12], using thin-skinned composites may accelerate the onset of observable changes in the mechanical, thermomechanical, and chemical properties that may result in lowered damage tolerance and structural integrity. As a result, investigating thin-skinned composite durability at the early stages of thermooxidative degradation is a crucial issue that needs to be understood to avoid premature in-service failures.

Thermal-oxidative aging may irreversibly change the chemical structure of polymer matrix composites $[13,14]$. Alterations to the chemical structure during thermooxidative 
degradation include postcuring $[1,9,13,15-22]$, loss of volatiles [2, 23-27], dehydration [13, 28, 29], chain scission [25, 30-34], additional cross-linking [1, 13], and carbonyl growth $[19,29]$. The initial chemical changes are accompanied by dehydration of secondary alcohols and the release of low molecular weight gaseous species due to random chain scission. However, at moderate heat exposures $\left(24^{\circ} \mathrm{C}-\right.$ $\left.177^{\circ} \mathrm{C}\right)$, chain cross-linking is the dominant chemical change in the matrix compared to chain scission [14]. Indeed, the increase in the cross-link density of the cured matrix primarily occurs during the initial aging period and is caused by postcure reactions $[13,17,35,36]$, which result in the excessive brittleness of the matrix [37]. As aging proceeds in the presence of oxygen, susceptible chemical structures in the resin are oxidized to various carbonyl containing groups. Therefore, matrix embrittlement increases with the oxygen concentration and aging time $[2,38]$. In addition to thermooxidative aging, the effects of physical aging [3941] should be considered. Physical aging is universal, is independent of any chemical change, and is related to the gradual densification of nonequilibrium glassy structures. These properties result in a higher modulus and strength, lower toughness, and slower relaxation (creep and stress relaxation). The aging is also accompanied by enthalpy relaxation. Physical aging can be accelerated by annealing, such as a thermal treatment below but not too far from the glass transition temperature. These parameters are exactly the conditions used for mild oxidative aging. The effects of postcuring and chemical and physical aging are inextricably combined in epoxy resins.

The thermomechanical behavior in organic matrix composites can be changed as a result of postcure reactions and physical aging induced by thermooxidative degradation. More precisely, the cross-linking density is increased by a continued postcure reaction and physical aging processes restrict the molecular movement in the main chain of the matrix $[17,35,41]$. The reduction in the molecular mobility results in an increase in the glass transition temperature $[2,17,39-41]$ and the storage modulus [20, 42-45]. In fact, an evaluation of the viscoelastic behavior can detect changes in the state of the molecular motion as functions of time and temperature $[39,46]$, which are responsible for relative stiffness in polymer matrix composites [39, 47, 48]. Storage modulus and the peak, shape, and the area under $\tan \delta$ curve are typically used as indicators in studies on molecular crosslinking [49].

Matrix densification affects the mechanical properties of OMCs (organic matrix composites) in the early stages of oxidative aging and is induced by physical aging and/or chemical aging (postcuring). Research conducted by Tsotsis et al. suggests that the matrix dependent properties are enhanced during the postcure stage and matrix degradation resulted from densification or increased chain scission in the thermosetting matrix polymers, respectively [1]. Other studies revealed that postcure reactions enhance the fiberdominant properties, such as the tensile strength and tensile modulus $[15,41,50,51]$, and decrease the matrix dominated properties, such as toughness $[3,52]$. Similarly, an increase in the tensile strength $[15,41]$ and modulus [53-56] and a reduction in the toughness [41] caused by physical aging have been observed by several researchers.

The thermooxidative degradation of organic matrix composites has been observed $[3,4,23,51,57,58]$ to be accompanied by the oxidation of the topmost surface of the matrix and by the formation of superficial microcracks. In fact, with continued aging, void formation occurred $[59,60]$ and cracks developed from crazing by increasing extensional stress [61]. A considerable amount of literature concluded that chemical shrinkage $[23,25,26,62-65]$ or notable variations in the matrix and fiber thermal expansion factors $[36,66]$ may provide dilatational stresses (internal stresses) or synergistic effects of both. In addition, in morphological investigations, fiber-matrix interfacial adhesion also degraded and weakened as a result of moderate heat exposure [3, 67-69], resulting in fiber pullout failures as part of the fracture mode [70-73].

In this study, the influence of thermooxidative degradation on the durability of glass fiber-reinforced epoxy composite is evaluated from mechanical, chemical, and physical perspectives. This work seeks to relate the premature alterations in the thin-skinned composite panel to the deterioration of its durability. Examining thermal-oxidative degradation using a principles-based approach and by considering the original composite thickness aids in assessing the actual toughness behavior available for the use condition by mechanical testing. As a result, measuring the toughness value by calculating the area under the stress-strain curve method was used instead of the Charpy impact test due to the subsize thickness of the material available. Furthermore, the methodology introduced here is based on industrial interest because the thermooxidative aging of such thin-skinned composites has not received a great deal of attention. Therefore, this study is anticipated to contribute to the body of literature on the materials used for the manufacturing of aircraft and especially to the durability of the materials in terms of the pronounced short-term thermal-oxidative degradation.

This study uses aging of plain GFRPs (glass fiberreinforced plastics) laminates exposed to air for $800 \mathrm{~h}$ at a temperature of $82^{\circ} \mathrm{C}$. Various tests are conducted to characterize the deterioration of the material, including tensile testing, dynamic mechanical analysis (DMA), Fouriertransformed infrared spectroscopy (FTIR), weight loss measurements, Scanning Electron Microscopy (SEM), and differential scanning calorimetry (DSC).

\section{Material}

The primary material used in the manufacturing of the plain laminates is the EHG250-68-37 prepreg. EHG250-6837 prepreg is comprised of an E-glass fabric impregnated with the DGEBA based epoxy resin EH250 and manufactured using the US 7781 standard. The epoxy resin is a product of the Gurit Company. Based on the recommendation of the manufacturer, the laminates were cured in an autoclave [74]. The length of the panel coincided with the plain weave on the weft direction. This coincidence stems from the proper stacking orientation of the four prepreg plies. Before cutting the $1 \mathrm{~mm}$ thick panels into appropriate test pieces using a 
$\mathrm{CNC}$ machine, the material was inspected using an ultrasonic C-scan to identify any defects.

\section{Experimental}

3.1. Isothermal Aging. In accordance with the ASTM D5229/D5229M standard, the samples used in this study were dried to a constant weight under vacuum conditions at a temperature of $70^{\circ} \mathrm{C}$ before aging [75]. This preliminary condition is essential because the matrix composite is hydrophilic in nature and variation in weight during aging serves as an oxidation index. To begin, the specimens were isothermally aged in an air circulating oven for a period of $800 \mathrm{~h}$ at $82^{\circ} \mathrm{C}$. The chosen temperature is slightly above the standard use temperature $\left(80^{\circ} \mathrm{C}\right)$ and is below $T_{g}\left(110^{\circ} \mathrm{C}\right.$ in TMA). For the sake of preventing damage to the specimen edges during pronounced thermooxidative aging, the edges were sealed using aluminum foil bonded with Dow Corning 3120 silicon rubber, which is stable at temperatures in excess of $300^{\circ} \mathrm{C}$. In addition, the relative humidity in the oven was reduced using phosphorus pentoxide. This thermal condition acts as an artificial thermooxidative aging condition to reproduce the use condition for the short-term applications.

3.2. Tensile Test. Using an Instron-5582 universal testing machine set at a $1 \mathrm{~mm} / \mathrm{min}$ crosshead speed, the static tensile tests were performed in accordance with ASTM D3039/D3039M [76]. Strain gauges were attached in the longitudinal direction (the weft direction axis of the specimen) to measure the tensile strain. The final values were taken from an average of the five specimens.

3.3. Dynamic Mechanical Analysis (DMA). A dynamic thermal analyzer (TA instrument model Q800) was used to conduct the thermal mechanical tests on both the aged and the unaged samples according to the ASTM D7028-07el standard [77]. A three-point bending geometry was used to apply deformation. The experiment was also conducted in scanning temperature mode, ranging from $25 \pm 2$ to $250^{\circ} \mathrm{C}$. Other conditions include a $5^{\circ} \mathrm{C} / \mathrm{min}$ heating rate and a $1.0 \mathrm{~Hz}$ oscillating frequency.

3.4. FTIR Spectroscopy. From the aged and unaged samples, approximately $2 \mathrm{mg}$ of the previously dried composite was used for the FTIR. The milled sample was pressed into a disc after being mixed with approximately $50 \mathrm{mg}$ of anhydrous Potassium Bromide (KBr). Spectra were acquired in the transmission mode using a Thermo Nicolet Nexus 470 FTIR spectrometer. The disc analysis was performed by treating the $\mathrm{KBr}$ as the background reference. Acquisition of the spectra was performed over a range from 4000 to $400 \mathrm{~cm}^{-1}$. Afterward, three separate analyses were conducted on each pallet at different locations to ensure the results were consistent.

3.5. Weight Loss Measurements. To monitor the weight loss from the samples over the $800 \mathrm{~h}$ oxidative aging at $82^{\circ} \mathrm{C}$, three specimens were cut from the original composite panel with a

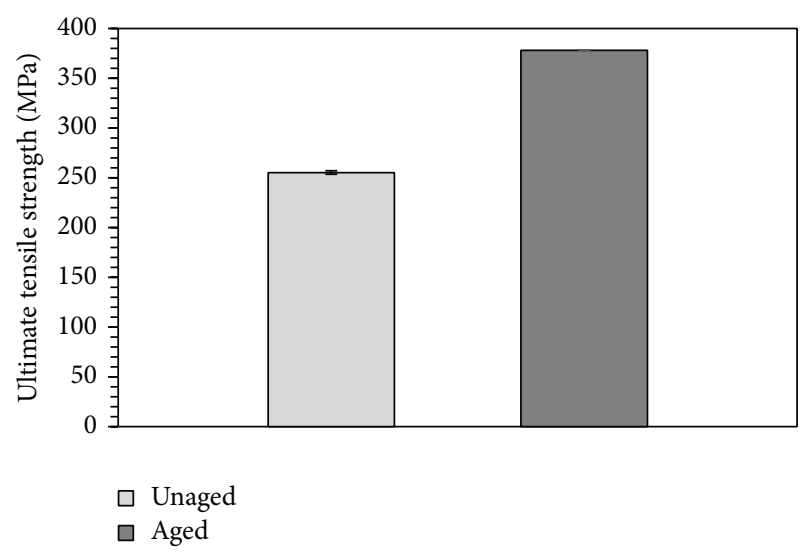

FIgURE 1: Change in ultimate tensile strength of EHG250-68-37 composite specimens subjected to $800 \mathrm{~h}$ oxidative aging at $82^{\circ} \mathrm{C}$.

width of approximately $20 \mathrm{~mm}$ and a length of approximately $75 \mathrm{~mm}$. In a periodic manner, the samples were removed from the oven, placed in a desiccator, and allowed to cool to room temperature. The samples were then weighed and returned to the oven. Weighing was performed using a microbalance accurate to within $10 \mu \mathrm{g}$. Each data point reported is an average of three separate specimens weighed independently.

3.6. Scanning Electron Microscopy (SEM). A Hitachi SU1510 SEM was used to investigate the superficial matrix morphology. Additional SEM analyses were performed on the cryofractured specimens using liquid nitrogen to study the fracture behavior of the composites and possibly any matrixfiber adhesion. In both morphological investigations, the surfaces of the specimens were sputter coated with gold. Additionally, observations were conducted on at least three different locations on the samples to ensure that the reported microphotograph represented the typical morphology.

3.7. Differential Scanning Calorimetry. The DSC measurements were performed using a DSC 823 system manufactured by Mettler Toledo with an air flow of $50 \mathrm{~mL} / \mathrm{min}$. A temperature scan was performed on $10 \mathrm{mg}$ prepreg samples (EHG25068-37) from $25^{\circ} \mathrm{C}$ to $250^{\circ} \mathrm{C}$ at a heating rate of $10^{\circ} \mathrm{C} / \mathrm{min}$.

\section{Results and Discussion}

4.1. Tensile Test. The comparison of both aged and unaged samples based on changes in the tensile strength and modulus is shown in Figures 1 and 2, respectively. The tensile strength and Young's modulus substantially increased under the pronounced aging conditions by $48 \%$ and $59 \%$, respectively. These changes may be attributed to the increase in the crosslinking density of the epoxy matrix as a result of simultaneous postcuring and physical aging during thermooxidative degradation [15, 41]. To be more precise, by increasing cross-linking density, the cross-linked network within the epoxy matrix will bear the majority of the induced loads in the composite material [13]. Consequently, the tensile 


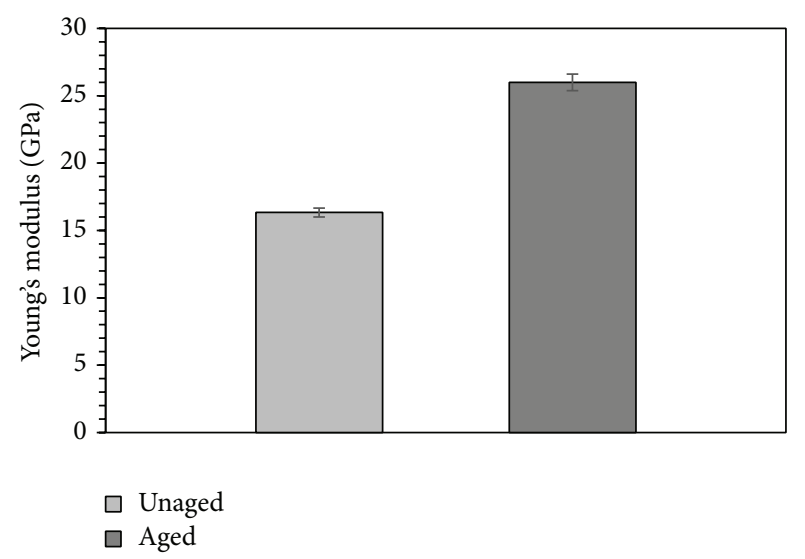

FIGURE 2: Change in Young's modulus of EHG250-68-37 composite specimens subjected to $800 \mathrm{~h}$ oxidative aging at $82^{\circ} \mathrm{C}$.

strength and modulus of elasticity rose significantly over the prolonged aging period.

However, a $0.22 \%$ drop in strain-to-failure value was observed after pronounced oxidative aging process, as shown in Figure 3. Furthermore, the toughness measured by the area under the stress-strain curve decreased considerably by $49 \%$ after $800 \mathrm{~h}$ aging at $82^{\circ} \mathrm{C}$ compared to original sample, as shown in Figure 4. This remarkable loss in toughness and strain to failure may be explained by the embrittlement of the epoxy matrix induced by postcuring [37], physical aging [41], and the oxygen concentration $[2,38]$.

4.2. Dynamic Mechanical Analysis (DMA). The influence of thermooxidative aging over a period of $800 \mathrm{~h}$ at $82^{\circ} \mathrm{C}$ on properties, such as the glass transition temperature $\left(T_{q}\right)$, the onset temperature, mechanical damping $(\tan \delta)$, and the storage modulus $\left(E^{\prime}\right)$, was studied by conducting dynamic mechanical thermal analyses. The glass transition temperature $\left(T_{g}\right)$ is taken as the temperature at which the loss factor is maximized. Additionally, the onset temperature is determined from an inflexion point in the modulus curve. Therefore, this measurement is less accurate than when measured from the $\tan \delta$ maximum temperature. However, the onset temperature is used more by aircraft manufacturers compared to the glass transition temperature $\left(T_{q}\right)$ [78-80].

As shown in Figure 5, the glass transition temperature $\left(T_{g}\right)$ increases moderately over the period of induced thermooxidative aging. Additionally, $\tan \delta$ peak in the aged composite is relatively narrow compared to the original sample. Table 1 shows a quantitative comparison of the area under $\tan \delta$ peak between the aged and unaged samples. The results show a $19 \%$ reduction in the area under the damping peak after the induced thermal aging. Moreover, there appears to be doubling of the loss peaks in the unaged specimens at higher temperatures. This finding may be attributable to an inhomogeneous network structure or to the diffusion controlled oxidation process being stronger near the surfaces.

The behavior of the dynamic storage modulus $\left(E^{\prime}\right)$ during the pronounced thermooxidative degradation is shown in Figure 6. A minor increase is observed at the glassy state $E^{\prime}$

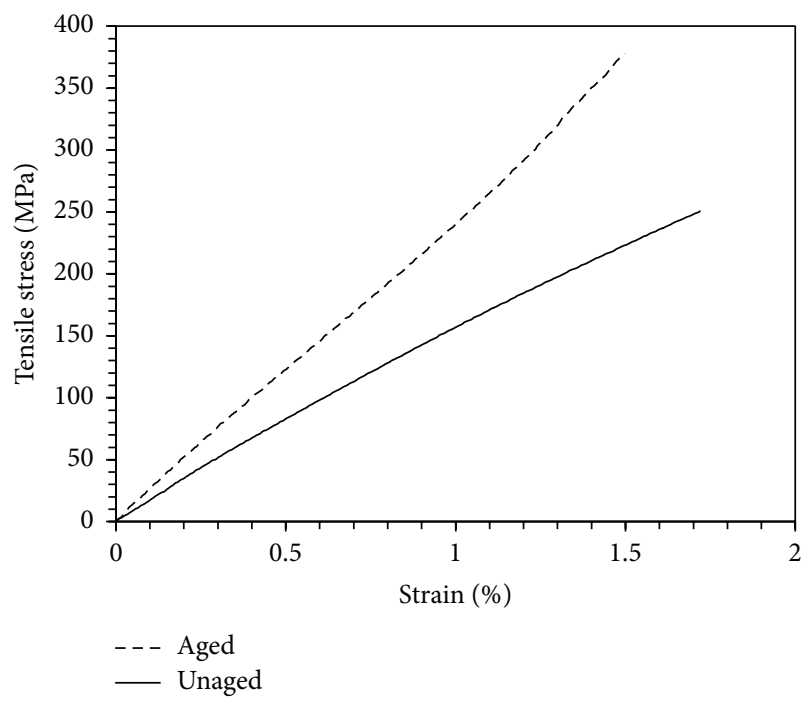

FIGURE 3: Stress-strain curves on EHG250-68-37 laminates before and after $800 \mathrm{~h}$ oxidative aging at $82^{\circ} \mathrm{C}$.

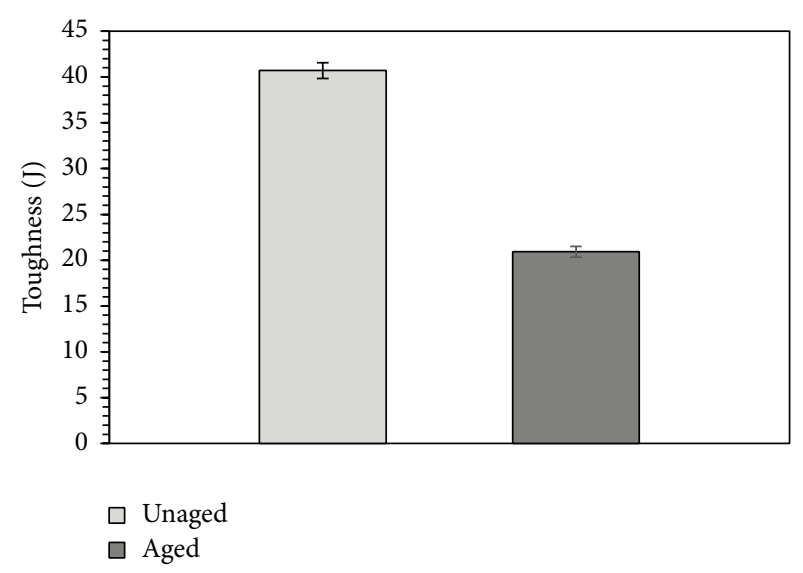

Figure 4: Change in toughness value of EHG250-68-37 composite specimens subjected to $800 \mathrm{~h}$ oxidative aging at $82^{\circ} \mathrm{C}$.

TABLE 1: Changes of $\tan \delta$ curve of EHG250-68-37 composite samples induced by $800 \mathrm{~h}$ thermooxidative degradation.

\begin{tabular}{lcc}
\hline Sample & $\tan \delta$ peak $\left({ }^{\circ} \mathrm{C}\right)$ & $\tan \delta$ peak area ${ }^{\mathrm{a}}(\mathrm{min})$ \\
\hline Unaged & 115.09 & 0.2382 \\
Aged & 129.72 & 0.1927 \\
\hline
\end{tabular}

${ }^{a}$ Area value indicates the area under $\tan \delta$ peak.

compared with the original sample. Moreover, a trend in the increased rubbery state $E^{\prime}$ with induced thermal aging is seen (Figure 6).

Figure 7 shows the changes in the onset temperature after the $800 \mathrm{~h}$ thermal-oxidative process at $82^{\circ} \mathrm{C}$ compared to the original composite. The onset temperature drops from $83.58^{\circ} \mathrm{C}$ to $80.58^{\circ} \mathrm{C}$, which is close to the maximum service temperature recommended by the manufacturer [74].

The observations above may be explained as follows. The alteration in $T_{g}, \tan \delta$ peak, and the storage modulus implies 


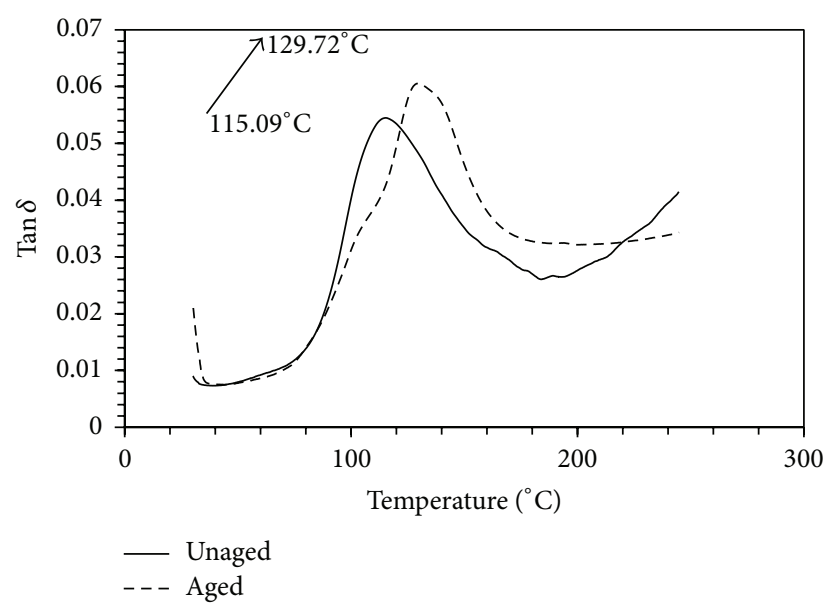

FIGURE 5: Alteration of $\tan \delta$ peak of EHG250-68-37 composite samples a $800 \mathrm{~h}$ thermooxidative aging at $82^{\circ} \mathrm{C}$.

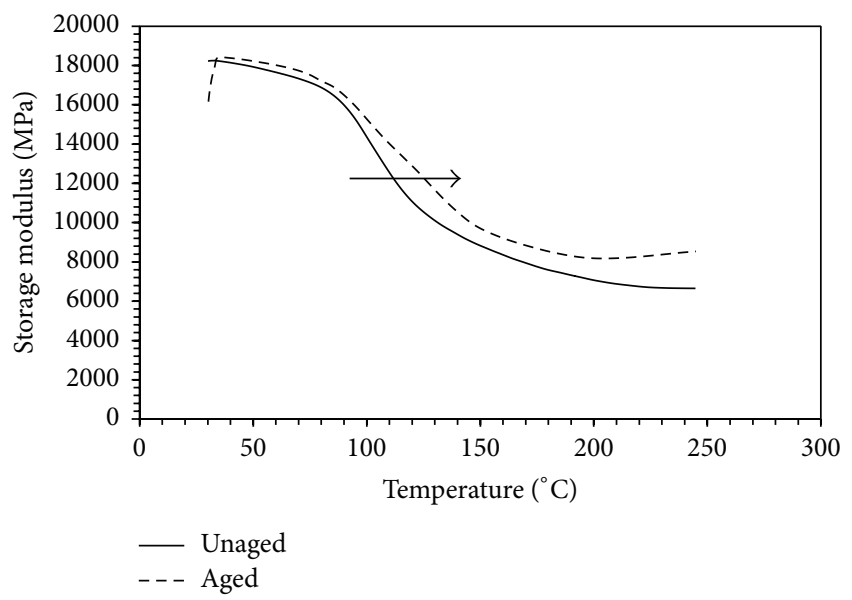

FIGURE 6: Viscoelastic trend of storage modulus before and after $800 \mathrm{~h}$ oxidative aging at $82^{\circ} \mathrm{C}$.

that the cross-link density of the matrix network's structure is being enhanced by the increasing temperature (as a result of postcuring and physical aging). Indeed, matrix densification results in the restriction of the molecular mobility, leading to a rise in the storage modulus and the glass transition temperature. However, the area under $\tan \delta$ peak decreases after the induced aging because of the increased cross-linking and steric hindrance in the matrix, which leads to a decrease in the damping capability (defined as the ability to absorb and dissipate energy or as the toughness) of the composite during pronounced aging conditions. This may be in accordance with the decrease in toughness observed in the tensile tests. Furthermore, the results from the onset temperature reveal that the thermal durability of the composite drops by approximately $3^{\circ} \mathrm{C}$. This, in turn, leads to premature mechanical failures.

4.3. FTIR Spectroscopy. In the hydroxyl regions $(\approx 3800-$ $2500 \mathrm{~cm}^{-1}$ ), we observe that for the pronounced aging condition the broad band of the spectra is centered at $3425 \mathrm{~cm}^{-1}$

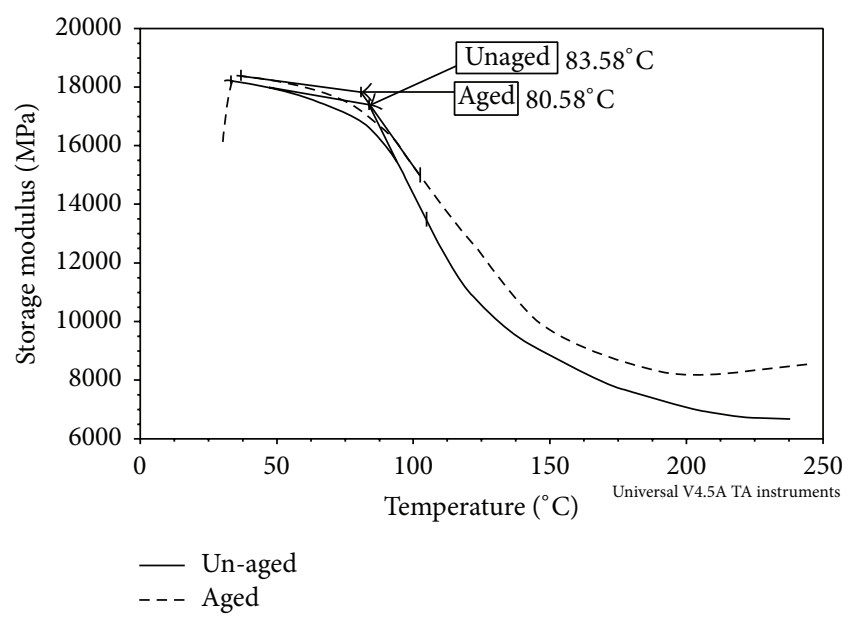

Figure 7: Changes in the onset temperature in EHG250-68-37 composite samples (initially and after $800 \mathrm{~h}$ thermooxidative aging in air at $82^{\circ} \mathrm{C}$ ).

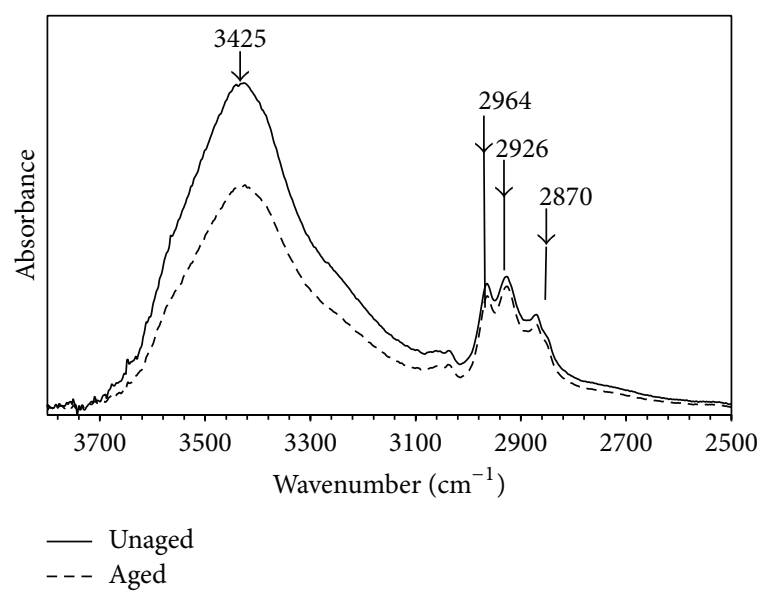

FIGURE 8: FTIR spectra of EHG250-68-37 composite sample in the hydroxyl and $\mathrm{CH}$ stretching regions (initially and after $800 \mathrm{~h}$ thermooxidative aging).

(corresponding to $\mathrm{O}-\mathrm{H}$ stretching of the hydroxyl group) and the peak at $2927 \mathrm{~cm}^{-1}$ (corresponding to C-H stretching of the methylene group) decreases in intensity, as shown in Figure 8. Additionally, a decrease in the absorption peak at $1095 \mathrm{~cm}^{-1}$ is noted as a result of the aging process (Figure 9). This decrease is responsible for the vibration of C-C-O associated with the secondary alcohol. From the changes in the peaks, we can deduce that the degradation of the epoxy resin originated in the - $\mathrm{C}-\mathrm{C}(\mathrm{OH})-\mathrm{C}$ - linkages. A theory was also formulated that the degradation of the epoxy resin secondary alcohol structure might be associated with the dehydration reaction that leads to the formation of $\mathrm{C}=\mathrm{C}$ bands [81-83]. A similar idea was also put forth where the degradation of the epoxy secondary alcohol structure may be attributed to the thermal-oxidative reaction that may lead to the formation of peroxides [84, 85]. From the FTIR observations, oxygen did not attack the material during the oxidative aging process to amine groups to form amide compounds. However, at 


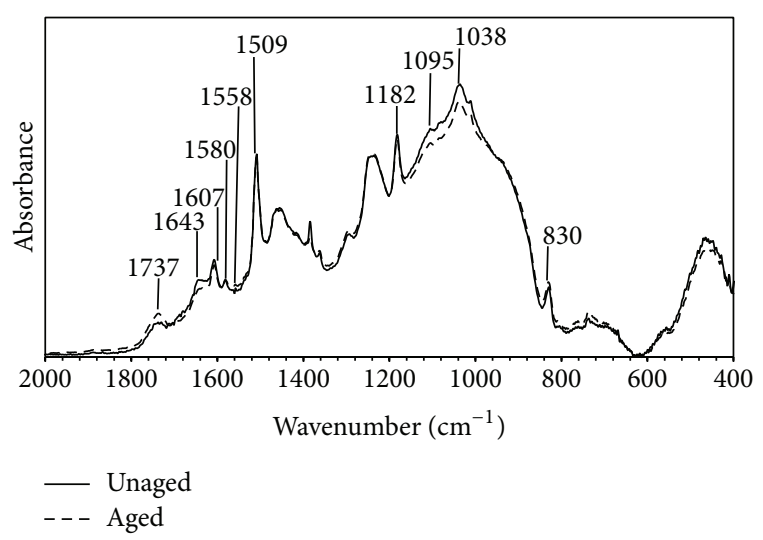

FIGURE 9: FTIR spectra of EHG250-68-37 composite sample in the fingerprint $\left(2000-400 \mathrm{~cm}^{-1}\right)$ domain (initially and after $800 \mathrm{~h}$ thermooxidative aging).

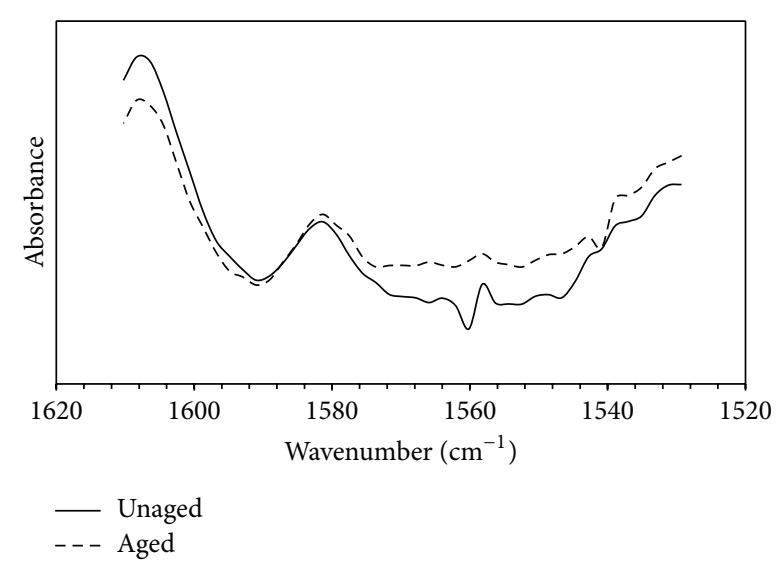

FIGURE 10: FTIR spectra of EHG250-68-37 composite sample from 1610 to $1530 \mathrm{~cm}^{-1}$ (initially and after $800 \mathrm{~h}$ thermooxidative aging).

approximately $830 \mathrm{~cm}^{-1}$, moderate growth was observed in the intensity of the peroxide group.

The IR spectra of the E250 epoxy system in the fingerprint region are shown in Figure 9. Although the absorption band at $915 \mathrm{~cm}^{-1}$ diminished or disappeared during the curing process, absorption of the $\mathrm{N}-\mathrm{H}$ group in the curing agent at $1560 \mathrm{~cm}^{-1}$ and $1580 \mathrm{~cm}^{-1}$ was observed in both the aged and virgin samples. However, as the aging time increased, the absorption band at $1560 \mathrm{~cm}^{-1}$ and $1580 \mathrm{~cm}^{-1}$ decreased, as shown in Figure 10. The reduction in these bands may be attributed to the moderate temperatures associated with the thermooxidative aging advancing the mobility of the molecular chains, which increases the reaction probability between the resin and the curing agent (known as the probability of densification) [35].

In the carbonyl region $\left(\approx 1900-1500 \mathrm{~cm}^{-1}\right)$, we observe that the absorbance of the band at $1737 \mathrm{~cm}^{-1}$, which corresponds to the characteristic stretching of $\mathrm{C}=\mathrm{O}$ in phenyl, slightly increased in intensity (Figure 11). The formation of carbonyl groups may result from the oxidation of aromatic ether groups in the resin $[19,29]$. This oxidation process is accompanied by a slight reduction in the intensity of the

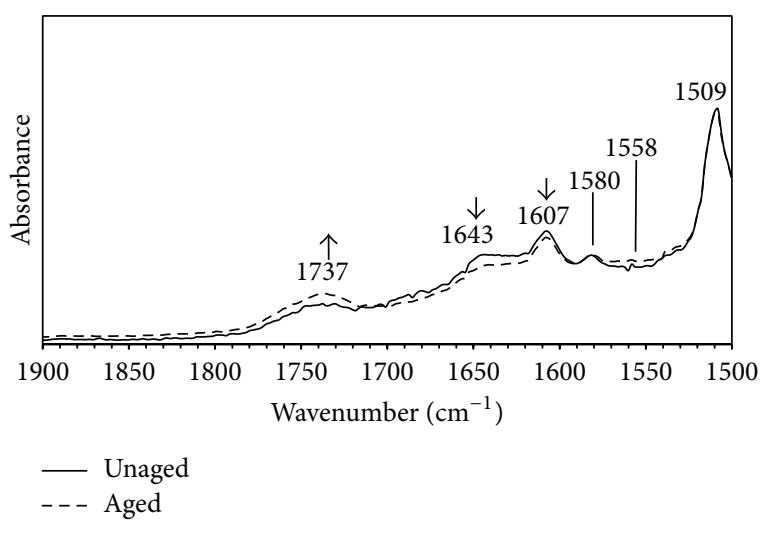

FIGURE 11: FTIR spectra of EHG250-68-37 composite sample in the carbonyl region (initially and after $800 \mathrm{~h}$ thermooxidative aging).

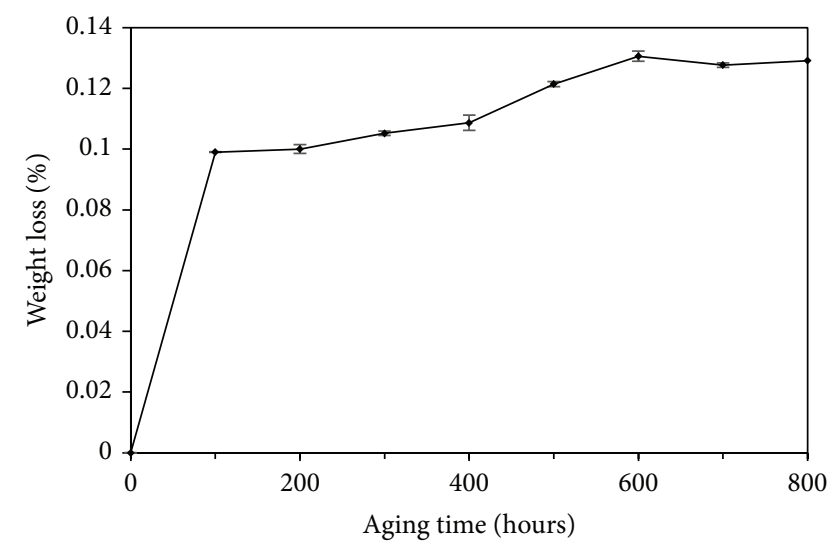

FIGURE 12: Weight loss of EHG250-68-37 composite sample during 800 hours of aging at $82^{\circ} \mathrm{C}$.

aromatic ether group, approximately $1035 \mathrm{~cm}^{-1}$ [29]. The overall oxidation rate is very slow, significantly more so than under the high temperature oxidation conditions [86], as shown by the very moderate increase in the carbonyl band, which is a sensitive measure of the degree of oxidation in all organic polymers.

4.4. Weight Loss Measurements. The weight loss percentage experienced by the composite specimens during the $800 \mathrm{~h}$ of thermooxidative aging at $82^{\circ} \mathrm{C}$ is depicted in Figure 12. The weight loss rises sharply during the initial $100 \mathrm{~h}$ of aging. This may be attributed to desorption of the residual moisture and volatiles and is not related to polymer degradation [27, 87]. A faster weight loss rate is evident over the 400 to $600 \mathrm{~h}$ range. Over this period, the mass loss rate reaches a peak of $0.13 \%$ at $600 \mathrm{~h}$ before staying constant over the remainder of the aging. This accelerated weight loss may occur due to the appearance of superficial cracks in the samples, which provide an increased surface area available to react with oxygen [88].

4.5. Scanning Electron Microscopy (SEM). After $800 \mathrm{~h}$ of thermooxidative degradation at $82^{\circ} \mathrm{C}$, notable changes occurred 


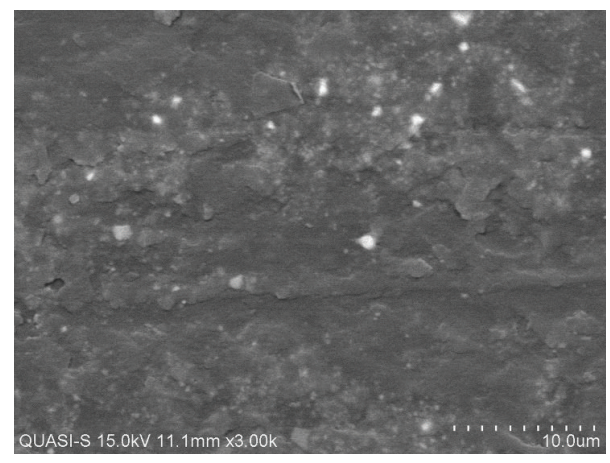

FIGURE 13: SEM micrograph of an unpolished surface after aging treatment.

on the sample surface. First, a SEM micrograph showing the microstructure of an unpolished sample is shown in Figure 13 in the backscattered electron mode. Due to different phase contrasts in the scattered electron distribution, oxidized carbonaceous layers appear as white spots on the matrix surface in contrast to the original resin surface. Next, a significant increase in the size and concentration of voids (indicated by arrows) in the aged sample becomes evident (Figure 14(b)), which may be explained as a result of the thermooxidative degradation process. In addition, a superficial crack is observed in Figure 14(b), which is a result of crazing from local stress concentrations and/or regions of microstructural inhomogeneity. Indeed, crazing forms from interlocked voids with extremely tightly drawn fibrils [61]. By increasing the extensional local stresses and matrix embrittlement induced by the elevated temperatures for a period of time, the fibrils are unable to absorb the dilatational thermal stress, which leads to the failure of fibrillated crazing structures and crack propagation.

The microscopic observations in the core cross-sectional area show the marginal effects of thermal degradation on the damage mechanisms that result in matrix shrinkage compared to the virgin sample (Figure 15). The resin shrinkage is related to the physical aging (densification) and/or volatilization of small molecular compounds during the postcure process. However, no evidence of fiber-matrix debonding caused by matrix shrinkage was observed. Therefore, the local stresses induced by resin shrinkage are insufficient to overcome fiber-matrix interfacial bonding but may be sufficient to weaken it.

Figure 16 illustrates the cryofractured sections of both the aged and unaged samples. An interesting observation from Figures 16(a) and 16(b) on the unaged sample is that the surfaces of the glass filaments have delicate coating of resin. This implies there is good bond strength between the matrix and the fiber. However, after temperature-induced degradation, the matrix completely detached from the filaments and fiber bundle, as shown in Figures 16(c) and 16(d), respectively. In addition, fiber pullout from the matrix was observed, as depicted in Figures 16(e) and 16(f). All the failure modes take the form of interfacial debonding, and the fiber pullout may be attributed to decreases in the interfacial fiber-matrix adhesion resulting from resin embrittlement as a

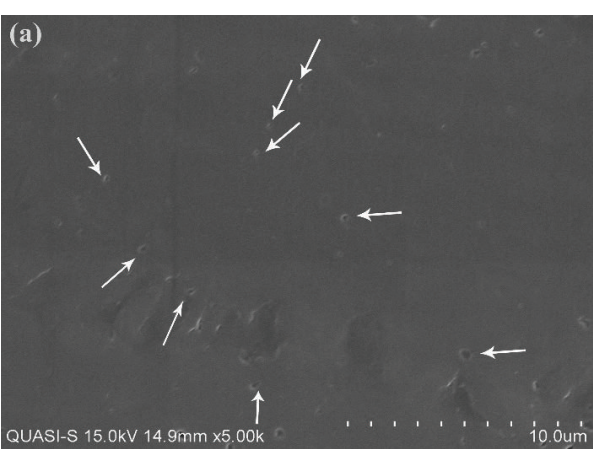

(a)

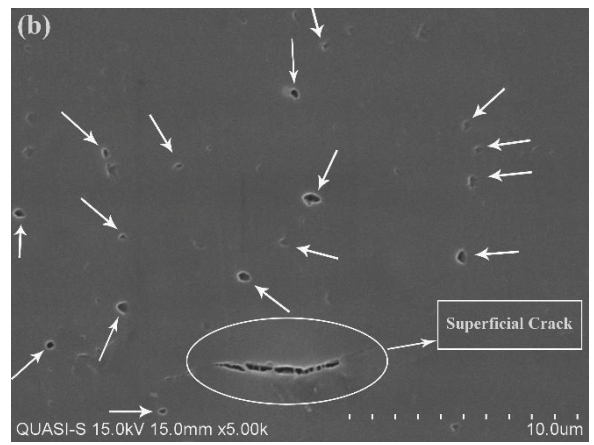

(b)

FIGURE 14: SEM observation on the polished matrix surface before (a) and after (b) $800 \mathrm{~h}$ thermooxidative aging at $82^{\circ} \mathrm{C}$.

result of thermal degradation. It is worth mentioning that the poor interfacial fiber-matrix bonding causes a reduction in interfacial dominant properties, such as the toughness. This reduction, in turn, leads to reduced damage tolerance and lack of long-term durability.

4.6. Differential Scanning Calorimetry. In addition to the DMA and FTIR analyses, DSC curves were also used to detect the possible postcuring and physical aging effects.

Figures 17 and 18 show the DSC curves for the unaged and aged specimens, respectively.

The differences are summarized as follows:

(i) $T_{g}$ calculated from the midpoint curved baseline $\left(\Delta c_{p}\right)$ shifts from 79.78 to $81.29^{\circ} \mathrm{C}$ after aging, which may indicate postcuring. These $T_{g}$ values should be compared to $\tan \delta$ maxima shown in Figure 5 (corresponding to 115.09 and $129.02^{\circ} \mathrm{C}$ ). It is well known that DSC usually determines the glass transition to be at lower temperatures than the DMA. The increase in $T_{g}$ is considerably larger in the DMA (approximately $14^{\circ} \mathrm{C}$ ) than in the DSC (approximately $1.5^{\circ} \mathrm{C}$ ). However, it should be noted that the DMA $\tan \delta$ curve of the aged specimen shown in Figure 5 is doubled, and there is a subcomponent close to the original one, which may correspond to the transition detected by the DSC. 


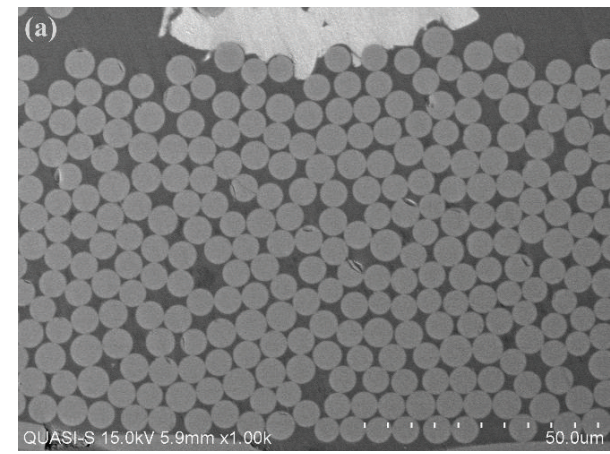

(a)

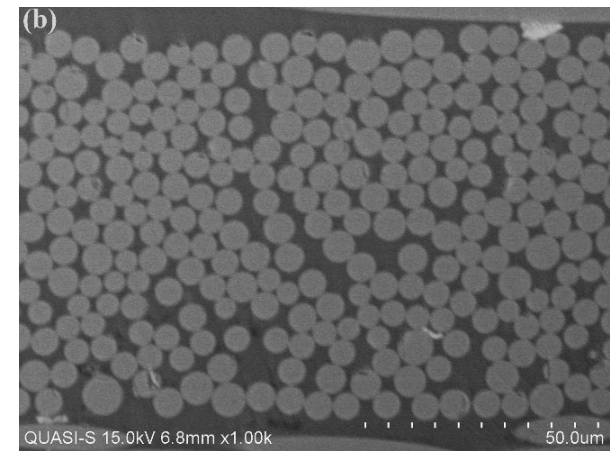

(b)

FIGURE 15: SEM micrographs of fiber ends at the cross-sectional area of unaged (a) and aged (b) sample.
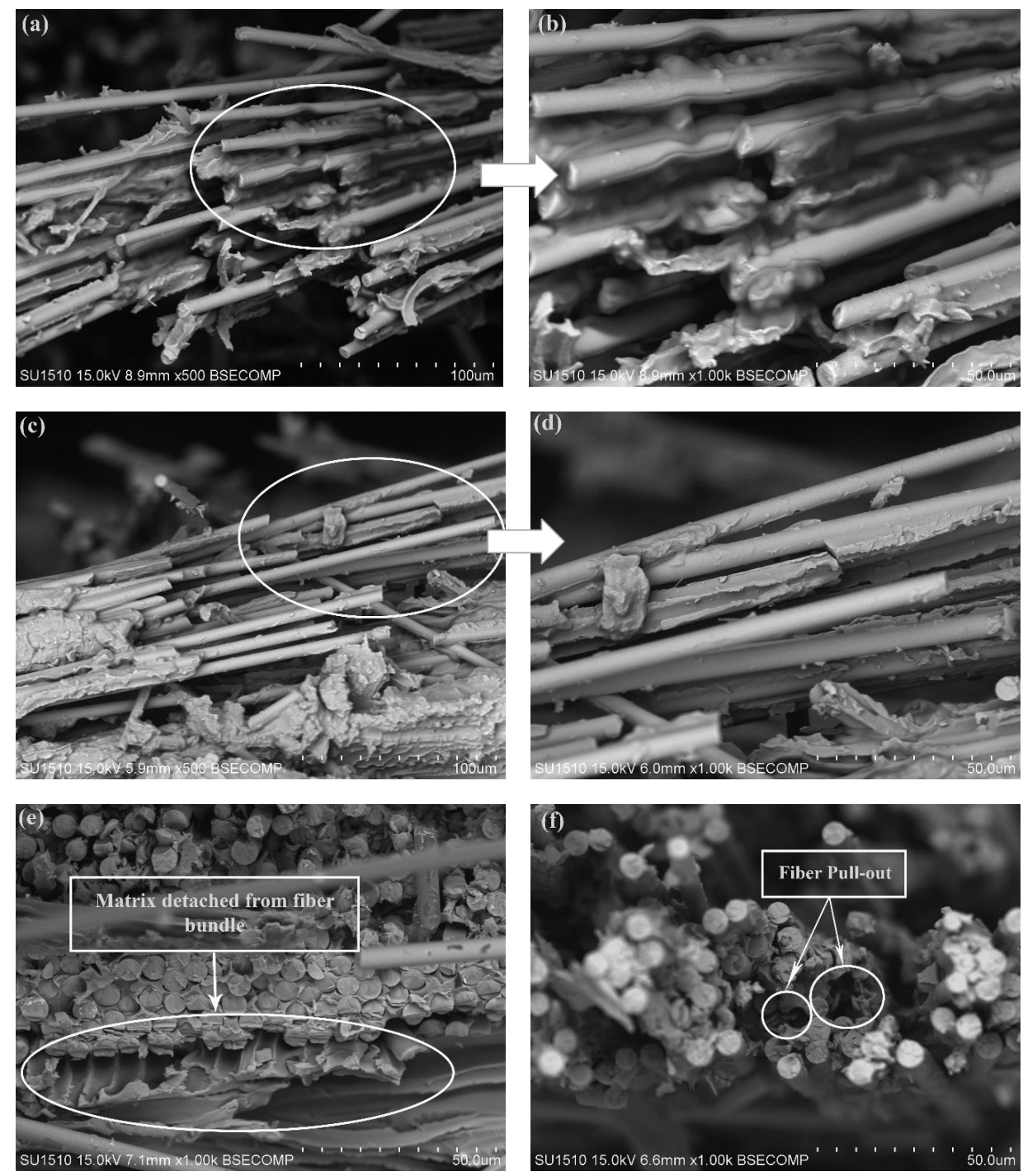

FIGURE 16: SEM observation on the cryofractured surface of EHG250-68-37 composite specimens; (a) fiber-matrix adhesion of unaged sample; (b) zoom on fiber-matrix adhesion corresponding to (a); (c) fiber-matrix adhesion of aged sample; (d) zoom on fiber-matrix adhesion corresponding to (c); (e) matrix detached from fiber bundle of aged sample; (f) fiber pullout of aged sample. 


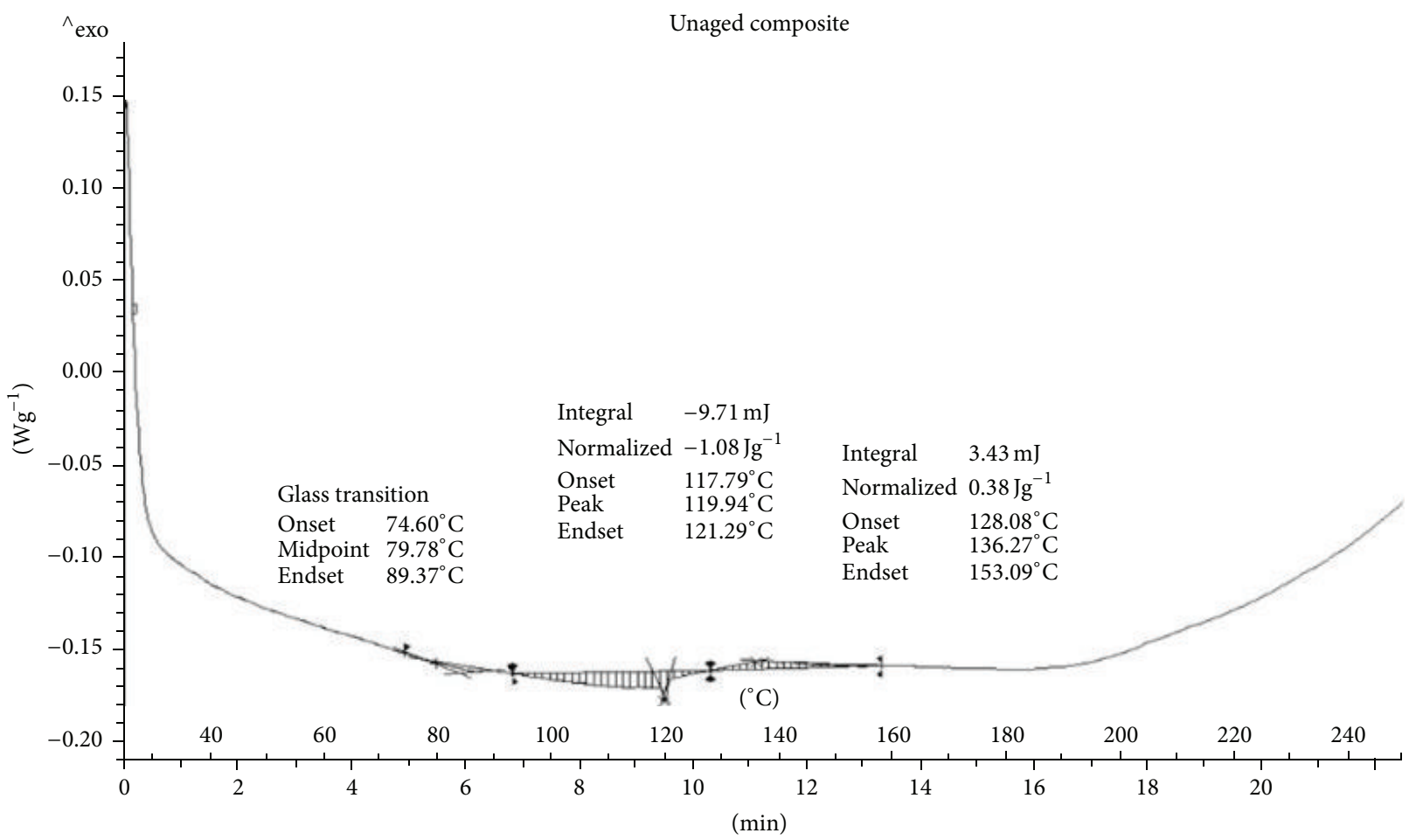

FIGURE 17: DSC curve of the unaged prepreg specimen.

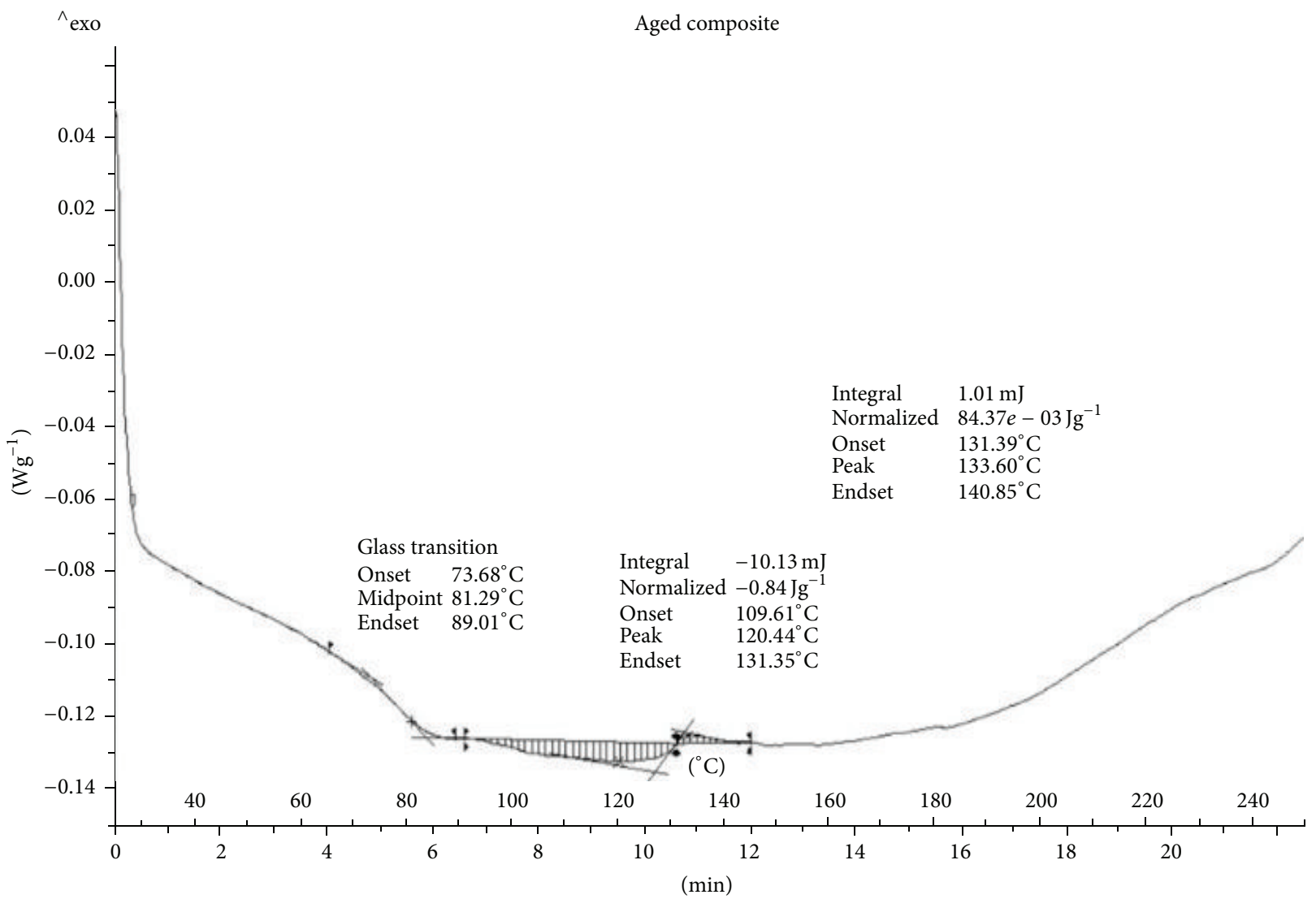

FIGURE 18: DSC curve of the aged prepreg specimen. 
(ii) The post- $T_{g}$ region of both DSC curves is complicated, and there are two broad, subsequent processes: one in the endothermal and one in the exothermal direction. Additionally, the unaged specimen exhibits a small but detectable melting peak, which disappears after aging. Under these conditions, the selection of the proper dividing line and the value of the integral obtained for the subprocesses are somewhat ambiguous. Nevertheless, we establish that the sharp melting disappears, the integral of the endotherm remains practically unchanged, and the integral of the exotherm decreases after aging. The interpretation (in the absence of the exact chemical composition) is tentative at best. The melting in the unaged specimen may be due to some unreacted component, which disappears after the thermal aging. The endotherm may be smeared overshoot attributable to physical aging (although it is usually sharper and increases with annealing) and the exotherm may be the residual reaction heat due to incomplete cross-linking, which diminishes after thermal aging (postcuring).

\section{Conclusions}

This study was designed based on industrial interests to evaluate the effect of thermooxidative aging on the durability of thin-skinned EHG 250-68-37 prepreg over a period of $800 \mathrm{~h}$ of isothermal aging at $82^{\circ} \mathrm{C}$. The results obtained from the mechanical, chemical, and physical experiments lead to the following conclusions:

(i) The tensile strength and modulus increase after aging, whereas the toughness measured by the area under the stress-strain curve decreases (due to lower elongation at break). These characteristics are probably attributable to the embrittlement of the matrix resin as a result of postcuring and oxygen concentration.

(ii) The glass temperature and the rubbery plateau modulus increase, which is clearly indicative of a postcuring process.

(iii) According to the FTIR observations, postcuring reactions occurred as the aging proceeded. Additionally, dehydration reactions cause the formation of secondary alcohol and aromatic ether groups in the resin, which are oxidized to carbonyl compounds.

(iv) From the electron microscopy observations, the presence of minor cracks resulting from postcuring is verified. However, no skin-core cracking is observed. In addition, matrix embrittlement induced by aging leads to fiber pullout and weakening of the fibermatrix adhesion.

(v) The overlap of the broad endothermal and exothermal process observed above $T_{g}$ in the DSC make an exact interpretation difficult, but a diminishing exotherm could be identified and is compatible with postcuring.

These findings suggest that, in general, matrix embrittlement resulted from postcure reactions and physical aging plays a significant role in reducing the durability of thinskinned composite by causing premature failures. This study provides a better understanding of the nominal useful structural life for such composite materials. However, one source of weakness in this research which limited the thermal and FTIR analyses was that the chemical structure and compositional data of the matrix were not revealed by the manufacturer. Finally, it is recommended that further research investigate the effect that thermooxidative aging has on the chemical structure of the toughening agent in the resin.

\section{Conflict of Interests}

The authors declare that there is no conflict of interests regarding the publication of this paper.

\section{Acknowledgment}

The authors would like to thank Ministry of Higher Education Malaysia for providing the research grants, Fundamental Research Grant Scheme (FRGS) 5524501 Fundamental Research Grant Scheme (FRGS) 5524499, for this research work.

\section{References}

[1] T. K. Tsotsis, S. Keller, K. Lee, J. Bardis, and J. Bish, "Aging of polymeric composite specimens for 5000 hours at elevated pressure and temperature," Composites Science and Technology, vol. 61, no. 1, pp. 75-86, 2001.

[2] H. Parvatareddy, J. Z. Wang, D. A. Dillard, T. C. Ward, and M. E. Rogalski, "Environmental aging of high-performance polymeric composites: effects on durability, Composites Science and Technology, vol. 53, no. 4, pp. 399-409, 1995.

[3] T. K. Tsotsis and S. M. Lee, "Long-term thermo-oxidative aging in composite materials: failure mechanisms," Composites Science and Technology, vol. 58, no. 3-4, pp. 355-368, 1998.

[4] T. K. Tsotsis, S. Keller, J. Bardis, and J. Bish, "Preliminary evaluation of the use of elevated pressure to accelerate thermooxidative aging in composites," Polymer Degradation and Stability, vol. 64, no. 2, pp. 207-212, 1999.

[5] T. A. Bullions, J. E. McGrath, and A. C. Loos, "Thermaloxidative aging effects on the properties of a carbon fiberreinforced phenylethynyl-terminated poly(etherimide)," Composites Science and Technology, vol. 63, no. 12, pp. 1737-1748, 2003.

[6] J. Wang, A. M. Waas, and H. Wang, "Experimental and numerical study on the low-velocity impact behavior of foamcore sandwich panels," Composite Structures, vol. 96, pp. 298311, 2013.

[7] M. Aktaş, C. Atas, B. M. Içten, and R. Karakuzu, "An experimental investigation of the impact response of composite laminates," Composite Structures, vol. 87, no. 4, pp. 307-313, 2009.

[8] S. Abrate, "Impact on laminated composite materials," Applied Mechanics Reviews, vol. 44, no. 4, pp. 155-190, 1991.

[9] S. Abrate, "Impact on laminated composites: recent advances," Applied Mechanics Reviews, vol. 47, no. 11, pp. 517-544, 1994.

[10] W. J. Cantwell and J. Morton, "The impact resistance of composite materials-a review," Composites, vol. 22, no. 5, pp. 347-362, 1991. 
[11] X. Colin and J. Verdu, "Mechanisms and kinetics of organic matrix thermal oxidation," in Long-Term Dura Poly Matrix Comp, K. V. Pochiraju, G. P. Tandon, and G. A. Schoeppner, Eds., pp. 311-344, Springer, New York, NY, USA, 2012.

[12] T. Tsotsis, "Thermo-oxidative ageing of composite materials," in Ageing of Composites, R. Martin, Ed., chapter 5, p. 135, Woodhead, Cambridge, UK, 2008.

[13] X. Lv, R. Wang, W. Liu, and L. Jiang, "Effect of thermal-oxidative aging on carbon fibre-bismaleimide composites," Pigment and Resin Technology, vol. 41, no. 1, pp. 34-41, 2012.

[14] T. S. Gates and M. A. Grayson, "On the use of accelerated aging methods for screening high temperature polymeric composite materials," in Collection of Technical Papers, AIAA/ASME/ASCE/AHS/ASC Structures, Structural Dynamics and Materials Conference, vol. 2, pp. 925-935, 1999.

[15] Y. Wang, J. Meng, Q. Zhao, and S. Qi, "Accelerated ageing tests for evaluations of a durability performance of glassfiber reinforcement polyester composites," Journal of Materials Science and Technology, vol. 26, no. 6, pp. 572-576, 2010.

[16] R. J. C. Carbas, L. F. M. Da Silva, E. A. S. Marques, and A. M. Lopes, "Effect of post-cure on the glass transition temperature and mechanical properties of epoxy adhesives," Journal of Adhesion Science and Technology, vol. 27, no. 23, pp. 2542-2557, 2013.

[17] C. Bockenheimer, D. Fata, and W. Possart, "New aspects of aging in epoxy networks. I. Thermal aging," Journal of Applied Polymer Science, vol. 91, no. 1, pp. 361-368, 2004.

[18] A. Cherdoud-Chihani, M. Mouzali, and M. J. M. Abadie, "Study of crosslinking AMS/DGEBA system by FTIR," Journal of Applied Polymer Science, vol. 69, no. 6, pp. 1167-1178, 1998.

[19] C. Galant, B. Fayolle, M. Kuntz, and J. Verdu, "Thermal and radio-oxidation of epoxy coatings," Progress in Organic Coatings, vol. 69, no. 4, pp. 322-329, 2010.

[20] L. Barral, J. Cano, A. J. López, J. Lopez, P. Nógueira, and C. Ramírez, "Thermal degradation of a diglycidyl ether of bisphenol A/1,3-bisaminomethylcyclohexane (DGEBA/1,3BAC) epoxy resin system," Thermochimica Acta, vol. 269-270, pp. 253-259, 1995.

[21] Y.-M. Pei, K. Wang, M.-S. Zhan, W. Xu, and X.-J. Ding, "Thermal-oxidative aging of DGEBA/EPN/LMPA epoxy system: chemical structure and thermal-mechanical properties," Polymer Degradation and Stability, vol. 96, no. 7, pp. 1179-1186, 2011.

[22] Y. Zahra, F. Djouani, B. Fayolle, M. Kuntz, and J. Verdu, "Thermo-oxidative aging of epoxy coating systems," Progress in Organic Coatings, vol. 77, no. 2, pp. 380-387, 2014.

[23] K. J. Bowles, D. Jayne, and T. A. Leonhardt, "Isothermal aging effects on PMR-15 resin," SAMPE Quarterly, vol. 24, no. 2, pp. 2-9, 1993.

[24] H.-M. Xiao, M.-S. Zhan, W. Xu, and X.-J. Ding, "Microstructure evolution of SW/EPN composites during hot air aging," Journal of Applied Polymer Science, vol. 131, no. 8, 2014.

[25] J. Decelle, N. Huet, and V. Bellenger, "Oxidation induced shrinkage for thermally aged epoxy networks," Polymer Degradation and Stability, vol. 81, no. 2, pp. 239-248, 2003.

[26] X. Colin and J. Verdu, "Strategy for studying thermal oxidation of organic matrix composites," Composites Science and Technology, vol. 65, no. 3-4, pp. 411-419, 2005.

[27] O. Ozcelik, L. Aktas, and M. C. Altan, "Thermo-oxidative degradation of graphite/epoxy composite laminates: modeling and long-term predictions," Express Polymer Letters, vol. 3, no. 12, pp. 797-803, 2009.
[28] Y.-L. Liu, W.-L. Wei, Y.-J. Chen, C.-S. Wu, and M.H. Tsai, "Novel thermosetting resins based on 4-(Nmaleimido)phenylglycidylether: III. Studies on the thermal degradation kinetics and mechanisms of the cured resins," Polymer Degradation and Stability, vol. 86, no. 1, pp. 135-145, 2004.

[29] B. Mailhot, S. Morlat-Thérias, M. Ouahioune, and J.-L. Gardette, "Study of the degradation of an epoxy/amine resin, 1 photo- and thermo-chemical mechanisms," Macromolecular Chemistry and Physics, vol. 206, no. 5, pp. 575-584, 2005.

[30] J.-S. Chen, C. K. Ober, M. D. Poliks, Y. Zhang, U. Wiesner, and C. Cohen, "Controlled degradation of epoxy networks: analysis of crosslink density and glass transition temperature changes in thermally reworkable thermosets," Polymer, vol. 45, no. 6, pp. 1939-1950, 2004.

[31] J. Wolfrum, S. Eibl, and L. Lietch, "Rapid evaluation of longterm thermal degradation of carbon fibre epoxy composites," Composites Science and Technology, vol. 69, no. 3-4, pp. 523-530, 2009.

[32] F. Awaja and P. J. Pigram, "Surface molecular characterisation of different epoxy resin composites subjected to UV accelerated degradation using XPS and ToF-SIMS," Polymer Degradation and Stability, vol. 94, no. 4, pp. 651-658, 2009.

[33] T. Dyakonov, P. J. Mann, Y. Chen, and W. T. K. Stevenson, “Thermal analysis of some aromatic amine cured model epoxy resin systems-II: residues of degradation," Polymer Degradation and Stability, vol. 54, no. 1, pp. 67-83, 1996.

[34] X. Buch and M. E. R. Shanahan, "Thermal and thermooxidative ageing of an epoxy adhesive," Polymer Degradation and Stability, vol. 68, no. 3, pp. 403-411, 2000.

[35] K. Li, K. Wang, M.-S. Zhan, and W. Xu, "The change of thermal-mechanical properties and chemical structure of ambient cured DGEBA/TEPA under accelerated thermo-oxidative aging," Polymer Degradation and Stability, vol. 98, no. 11, pp. 2340-2346, 2013.

[36] M. Akay and G. R. Spratt, "Evaluation of thermal ageing of a carbon fibre reinforced bismalemide," Composites Science and Technology, vol. 68, no. 15-16, pp. 3081-3086, 2008.

[37] B. G. Kumar, R. P. Singh, and T. Nakamura, "Degradation of carbon fiber-reinforced epoxy composites by ultraviolet radiation and condensation," Journal of Composite Materials, vol. 36, no. 24, pp. 2713-2733, 2002.

[38] T. Kelen, Polymer Degradation, Van Nostrand Reinhold, 1983.

[39] S. J. MacKenzie, T. J. Mulkern, and N. C. Beck Tan, "Material properties of bi-modal epoxy networks," Tech. Rep., Army Research Lab., Aberdeen Proving Ground, MD. Weapons and Materials Research Directorate, 2001.

[40] L. Barral, J. Cano, J. López et al., "Physical aging of a tetrafunctional/phenol novolac epoxy mixture cured with diamine DSC and DMA measurements," Journal of Thermal Analysis and Calorimetry, vol. 60, no. 2, pp. 391-399, 2000.

[41] G. M. Odegard and A. Bandyopadhyay, "Physical aging of epoxy polymers and their composites," Journal of Polymer Science Part B: Polymer Physics, vol. 49, no. 24, pp. 1695-1716, 2011.

[42] M. L. Costa, J. M. Paiva, E. C. Botelho, and M. C. Rezende, "Avaliação térmica e reológica do ciclo de cura do préimpregnado de carbono/epóxi," Polímeross: Ciência e Tecnologia, vol. 13, no. 3, pp. 188-197, 2003.

[43] C. D. Wingard, "Characterization of prepreg and cured epoxy/fiberglass composite material for use in advanced composite piping systems," Thermochimica Acta, vol. 357-358, pp. 293-301, 2000. 
[44] B. S. Hayes, E. N. Gilbert, and J. C. Seferis, "Scaling complications of dual temperature cure resin prepreg systems in airplane part manufacture," Composites Part A: Applied Science and Manufacturing, vol. 31, no. 7, pp. 717-725, 2000.

[45] S.-B. Shim, J. C. Seferis, Y. S. Eom, and Y. T. Shim, “Thermal characterization and comparison of structural prepregs with different cure temperatures," Thermochimica Acta, vol. 291, no. 1-2, pp. 73-79, 1997.

[46] R. P. Griffiths, Physical ageing effects in crosslinked epoxy resins [Ph.D. thesis], Brunel University London, Uxbridge, UK, 1988.

[47] S. Sankaran, K. R. Sekhar, G. Raju, and M. N. J. Kumar, "Characterization of epoxy syntactic foams by dynamic mechanical analysis," Journal of Materials Science, vol. 41, no. 13, pp. 40414046, 2006.

[48] E. M. Wouterson, F. Y. C. Boey, X. Hu, and S.-C. Wong, "Effect of fiber reinforcement on the tensile, fracture and thermal properties of syntactic foam," Polymer, vol. 48, no. 11, pp. 31833191, 2007.

[49] X.-M. Wang, B. Riedl, R. L. Geimer, and A. W. Christiansen, "Phenol-formaldehyde resin curing and bonding under dynamic conditions," Wood Science and Technology, vol. 30, no. 6, pp. 423-442, 1996.

[50] S. Marouani, L. Curtil, and P. Hamelin, "Ageing of carbon/epoxy and carbon/vinylester composites used in the reinforcement and/or the repair of civil engineering structures," Composites Part B: Engineering, vol. 43, no. 4, pp. 2020-2030, 2012.

[51] T. K. Tsotsis, "Long-term thermo-oxidative aging in composite materials: experimental methods," Journal of Composite Materials, vol. 32, no. 11, pp. 1115-1135, 1998.

[52] D. Lévêque, H. Katoh, J. Cinquin, and K. Hasegawa, "Durability evaluation of carbon/BMI composites after thermal aging," in Proceedings of the 18th International Conference on Composites Materials (ICCM '11), Jeju Island, Republic of Korea, August 2011.

[53] X. Shi, B. M. D. Fernando, and S. G. Croll, "Concurrent physical aging and degradation of crosslinked coating systems in accelerated weathering," Journal of Coatings Technology Research, vol. 5, no. 3, pp. 299-309, 2008.

[54] C. G.'Sell and G. B. McKenna, "Influence of physical ageing on the yield response of model DGEBA/poly(propylene oxide) epoxy glasses," Polymer, vol. 33, no. 10, pp. 2103-2113, 1992.

[55] H. W. Hu, "Physical aging in long term creep of polymeric composite laminates," Journal of Mechanics, vol. 23, no. 3, pp. 245-252, 2007.

[56] E. S.-W. Kong, G. L. Wilkes, J. E. McGrath, A. K. Banthia, Y. Mohajer, and M. R. Tant, "Physical aging of linear and network epoxy resins," Polymer Engineering \& Science, vol. 21, no. 14, pp. 943-950, 1981.

[57] T. K. Tsotsis, S. M. Keller, K. Lee, J. Bardis, and J. Bish, "3000 hours aging of polymeric composite specimens under elevated pressure and temperature," in Proceedings of the 44th International SAMPE Symposium, Long Beach, Calif, USA, 1999.

[58] T. K. Tsotsis, "Thermo-oxidative aging of composite materials," Journal of Composite Materials, vol. 29, no. 3, pp. 410-422, 1995.

[59] P. Woelke, N. Abboud, and I. Sandler, "Framework for constitutive modeling and life prediction for polymeric matrix composites," in Proceedings of the SEM Annual Conference and Exposition on Experimental and Applied Mechanics, vol. 4, pp. 2416-2418, Society for Experimental Mechanics, Albuquerque, NM, USA, June 2009.
[60] M. S. Madhukar, K. J. Bowles, and D. S. Papadopoulos, "Thermo-oxidative stability and fiber surface modification effects on the inplane shear properties of graphite/PMR-15 composites," Journal of Composite Materials, vol. 31, no. 6, pp. 596-618, 1997.

[61] A. S. Maxwell, R. W. Broughton, D. G. Dean, and D. G. Sims, "Review of accelerated ageing methods and lifetime prediction techniques for polymeric materials," NPL Report DEPC-MPR 016, 2005.

[62] D. Q. Vu, M. Gigliotti, and M. C. Lafarie-Frenot, "Experimental characterization of thermo-oxidation-induced shrinkage and damage in polymer-matrix composites," Composites Part A: Applied Science and Manufacturing, vol. 43, no. 4, pp. 577-586, 2012.

[63] M. C. Lafarie-Frenot and S. Rouquie, "Influence of oxidative environments on damage in c/epoxy laminates subjected to thermal cycling," Composites Science and Technology, vol. 64, no. 10-11, pp. 1725-1735, 2004.

[64] K. J. Bowles, D. S. Papadopoulos, L. L. Inghram, L. S. McCorkle, and O. V. Klan, "Longtime durability of PMR15 matrix polymer at 204, 260, 288, and $316^{\circ}$ C," NASA TM-2001-210602, 2001.

[65] D.-Q. Vu, M. Gigliotti, and M. C. Lafarie-Frenot, "The effect of thermo-oxidation on matrix cracking of cross-ply [0/90] composite laminates," Composites Part A: Applied Science and Manufacturing, vol. 44, no. 1, pp. 114-121, 2013.

[66] P. E. McMahon, "Thermal oxidative resistance of carbon fibres and their composites," in Proceedings of the 23rd National SAMPE Symposium Proceedings, vol. 23, p. 150, 1978.

[67] K. J. Bowles, M. Madhukar, D. S. Papadopoulos, L. Inghram, and L. Mccorkle, "The effects of fiber surface modification and thermal aging on composite toughness and its measurement," Journal of Composite Materials, vol. 31, no. 6, pp. 552-579, 1997.

[68] I. Jangchud, R. K. Eby, A. M. Serrano, and M. A. Meador, "Studies of PAN-based carbon fiber surfaces: their influence on interfacial bonding with PMR-15 polyimide and composite thermo-oxidative stability," Journal of Advanced Materials, vol. 28, no. 1, pp. 19-25, 1996.

[69] D. A. Scola, B. L. Laube, and J. H. Vontell, "Interface characteristics of isothermally aged high temperature graphite fiber/PMR15 composites," in Controlled Interphases in Composite Materials: Proceedings of the Third International Conference on Composite Interfaces (ICCI-III) Held on May 21-24, 1990 in Cleveland, Ohio, USA, part 1, pp. 17-36, Springer, 1990.

[70] N. E. Zafeiropoulos, C. A. Baillie, and J. M. Hodgkinson, "Engineering and characterisation of the interface in flax fibre/polypropylene composite materials. Part II. The effect of surface treatments on the interface," Composites Part A Applied Science and Manufacturing, vol. 33, no. 9, pp. 1185-1190, 2002.

[71] A. Kausar, "Fabrication and properties of polyamide and graphene oxide coated carbon fiber reinforced epoxy composites," American Journal of Polymer Science, vol. 4, no. 3, pp. 8893, 2014.

[72] I. Dlouhy, Z. Chlup, D. N. Boccaccini, S. Atiq, and A. R. Boccaccini, "Fracture behaviour of hybrid glass matrix composites: thermal ageing effects," Composites Part A: Applied Science and Manufacturing, vol. 34, no. 12, pp. 1177-1185, 2003.

[73] A. G. Evans and F. W. Zok, "The physics and mechanics of fibre-reinforced brittle matrix composites," Journal of Materials Science, vol. 29, no. 15, pp. 3857-3896, 1994.

[74] EHG250-68-37.pdf.2015, https://www.yumpu.com/en/document/ view/9044772/ehg250-68-37-prepreg-materials-for-secondarystructures-gurit. 
[75] ASTM D5229/D5229M-14, Standard Test Method for Moisture Absorption Properties and Equilibrium Conditioning of Polymer Matrix Composite Materials, 2015.

[76] ASTM International, "Standard test method for tensile properties of polymer matrix composite materials," ASTM D3039/D3039M-14, ASTM International, West Conshohocken, Pa, USA, 2015.

[77] ASTM International, "Standard test method for glass transition temperature (DMA Tg) of polymer matrix composites by dynamic mechanical analysis (DMA)," ASTM D7028-07el, ASTM International, West Conshohocken, Pa, USA, 2015.

[78] B. Dao, J. Hodgkin, J. Krstina, J. Mardel, and W. Tian, "Accelerated ageing versus realistic ageing in aerospace composite materials. III. The chemistry of thermal ageing in bismaleimide based composites," Journal of Applied Polymer Science, vol. 105, no. 4, pp. 2062-2072, 2007.

[79] B. Dao, J. Hodgkin, J. Krstina, J. Mardel, and W. Tian, "Accelerated aging versus realistic aging in aerospace composite materials. I. The chemistry of thermal aging in a low-temperature-cure epoxy composite," Journal of Applied Polymer Science, vol. 102, no. 5, pp. 4291-4303, 2006.

[80] B. Dao, J. Hodgkin, J. Krstina, J. Mardel, and W. Tian, "Accelerated aging versus realistic aging in aerospace composite materials. II. Chemistry of thermal aging in a structural composite," Journal of Applied Polymer Science, vol. 102, no. 4, pp. 3221-3232, 2006.

[81] N. Grassie, M. I. Guy, and N. H. Tennent, "Degradation of epoxy polymers: part 4-thermal degradation of bisphenolA diglycidyl ether cured with ethylene diamine," Polymer Degradation and Stability, vol. 14, no. 2, pp. 125-137, 1986.

[82] Y.-L. Liu, G.-H. Hsiue, C.-W. Lan, and Y.-S. Chiu, "Phosphoruscontaining epoxy for flame retardance: IV. Kinetics and mechanism of thermal degradation," Polymer Degradation and Stability, vol. 56, no. 3, pp. 291-299, 1997.

[83] N. Rose, M. Le Bras, R. Delobel, B. Costes, and Y. Henry, "Thermal oxidative degradation of an epoxy resin," Polymer Degradation and Stability, vol. 42, no. 3, pp. 307-316, 1993.

[84] S. C. Lin, B. J. Bulkin, and E. M. Pearce, "Epoxy resins. III. Application of fourier transform IR to degradation studies of epoxy systems," Journal of Polymer Science Part A-1: Polymer Chemistry, vol. 17, no. 10, pp. 3121-3148, 1979.

[85] P. Musto, G. Ragosta, P. Russo, and L. Mascia, "Thermaloxidative degradation of epoxy and epoxy-bismaleimide networks: kinetics and mechanism," Macromolecular Chemistry and Physics, vol. 202, no. 18, pp. 3445-3458, 2001.

[86] S. Bondzic, J. Hodgkin, J. Krstina, and J. Mardel, "Chemistry of thermal ageing in aerospace epoxy composites," Journal of Applied Polymer Science, vol. 100, no. 3, pp. 2210-2219, 2006.

[87] I. Ammar-Khodja, C. Picard, M. Fois, C. Marais, and P. Netchitailo, "Preliminary results on thermo-oxidative ageing of multi-hole carbon/epoxy composites," Composites Science and Technology, vol. 69, no. 9, pp. 1427-1431, 2009.

[88] J. A. Hinkley and J. W. Connell, "Resin systems and chemistry: degradation mechanisms and durability," in Long-Term Durability of Polymeric Matrix Composites, K. V. Pochiraju, G. P. Tandon, and G. A. Schoeppner, Eds., pp. 1-37, Springer, New York, NY, USA, 2012. 

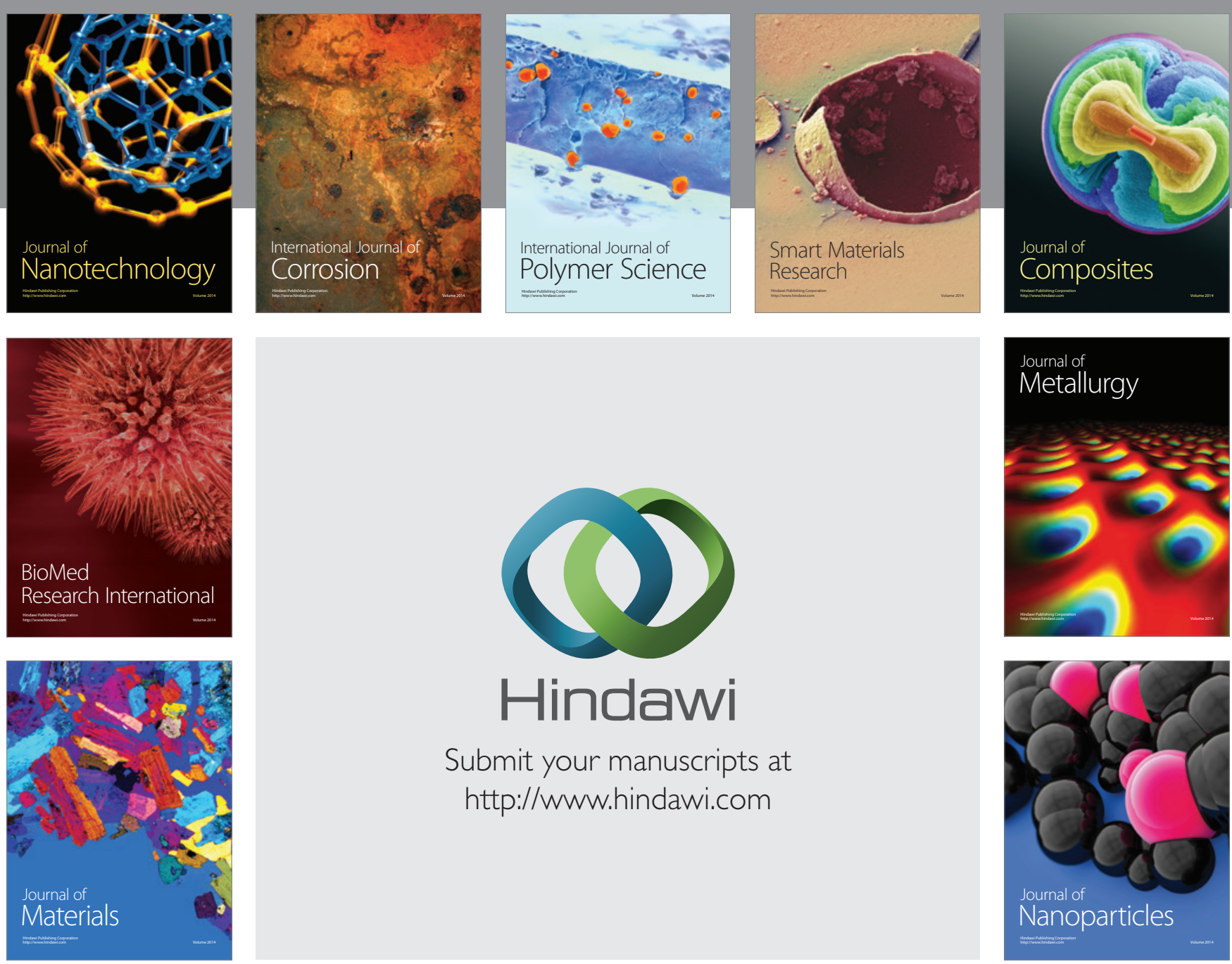

Submit your manuscripts at http://www.hindawi.com
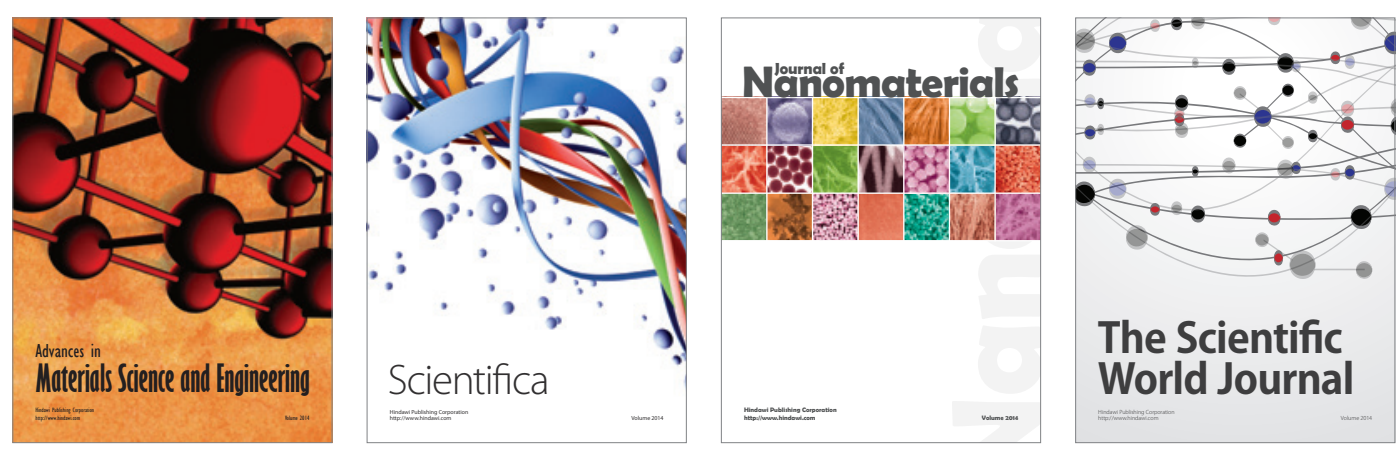

\section{The Scientific World Journal}
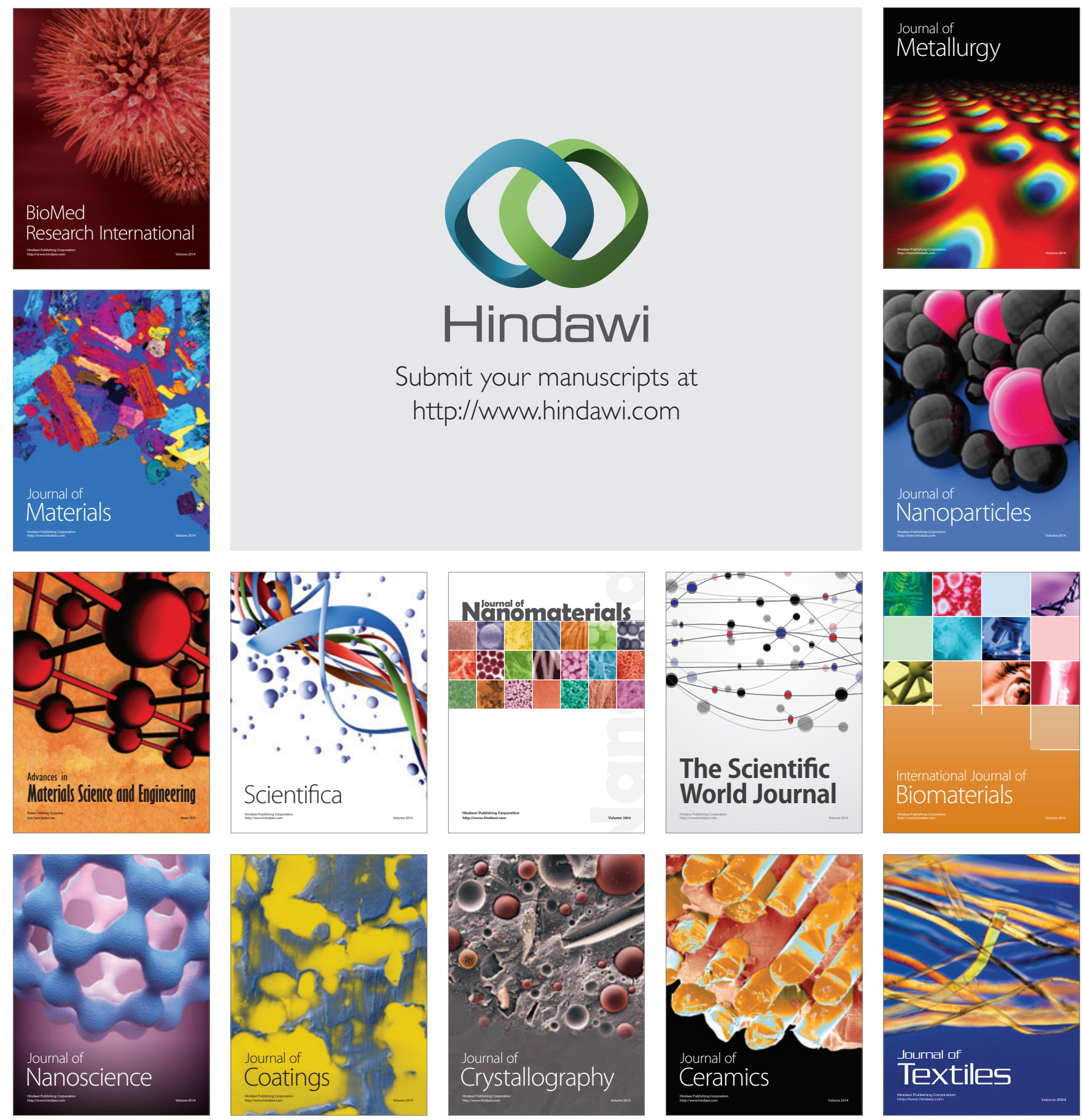